100 | Pengembangan Panduan Solution Focused Brief Counseling Untuk Guru Bk Sekolah Menengah Pertama Negeri (Smpn) 1 Kota Kediri

PENGEMBANGAN PANDUAN

\title{
SOLUTION FOCUSED BRIEF COUNSELING UNTUK GURU BK SEKOLAH MENENGAH PERTAMA NEGERI (SMPN) 1 KOTA KEDIRI
}

\author{
Laelatul Arofah \\ Bimbingan dan Konseling, Fakultas Keguruan dan Ilmu Pendidikan, Universitas Nusantara PGRI Kediri \\ laelatularofah@unpkediri.ac.id
}

\author{
Rosalia Dewi Nawantara \& Arinda Dwi Puspitasari \\ Bimbingan dan Konseling, Fakultas Keguruan dan Ilmu Pendidikan, Universitas Nusantara PGRI Kediri \\ rosaliadewi@unpkediri.ac.id \& $\underline{\text { arinda.airin@gmail.com }}$
}

\begin{abstract}
Abstrak
Salah satu bentuk profesionalisme guru BK dalam praktik konseling yaitu melakukan konseling dengan tahapan yang sesuai dengan pendekatan yang dilakukan. Berbagai pendekatan dalam konseling cukup beragam, dan salah satunya adalah SFBC (Solution Focused Brief Counseling) atau sering dikenal dengan konseling ringkas berfokus solusi. Konseling ini memfokuskan pada solusi yang dibangun oleh konseli, bukan pada masalahnya. Konseli diajak untuk membangun solusinya sendiri dengan berpegang pada kemampuan yang dimiliki konseli. Akan tetapi kenyataan yang terjadi dilapangan menunjukkan bahwa para guru BK di sekolah belum mengenal pendekatan SFBC ini. Sehingga peneliti tertarik untuk mengembangkan panduan SFBC untuk siswa Sekolah Menengah Pertama (SMP) dengan tujuan agar guru BK memiliki tambahan pengetahuan seputar pendekatan konseling. Penelitian ini menggunakan pendekatan penelitian research and development. Penelitian dan pengembangan ini menggunakan tujuh tahap yaitu 1) tahap pengumpulan data; 2) tahap perencanaan;3) mengembangkan produk awal; 4) uji coba terhadap ahli materi BK dan media; 5) revisi media; 6) uji calon pengguna produk; dan 7) revisi tahap akhir. Berdasarkan hasil penilaian uji ahli materi BK, ahli media, dan calon pengguna produk, maka diperoleh deskripsi penerimaan pemakai atas bentuk dan isi dari panduan konseling SFBC untuk guru BK SMPN 1 Kota Kediri. Beberapa aspek yang menujukkan keberterimaan panduan Solution Focused Brief Counseling dari ahli materi BK, ahli media, dan calon pengguna produk meliputi aspek ketepatan, kesesuaian, kejelasan, dan kemenarikan. Tiap aspek tersebut dinilai oleh para ahli dan calon pengguna produk yang secara keseluruhan menunjukkan kategori sangat baik.
\end{abstract}

Kata Kunci: solution focused brief counseling, guru BK, layanan konseling

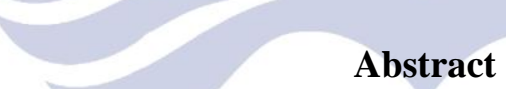

One form of professionalism BK teachers in the practice of counseling is to conduct counseling with stages in accordance with the approach undertaken. Counseling approaches are quite diverse, and one of them is SFBC (Solution Focused Brief Counseling) or often known as concise solution-focused counseling. This counseling focuses on the solution built by the counselee, not the problem. The counselee is invited to build his own solution by holding on to the ability of the counselee. However, the reality that occurred in the field showed that BK teachers in schools have not been familiar with this SFBC approach. So researchers are interested in developing SFBC guides for Junior High School students with the aim that BK teachers have additional knowledge about counseling approaches. This research uses research and development research approach. This research and development uses seven stages namely 1) data collection phase; 2) planning stage; 3) develop the initial product; 4) a trial of BK material experts and the media; 5) media revision; 6) test prospective users of the product; and 7) final-stage revisions. Based on the results of the assessment of BK material experts, media experts, and prospective users of the product, the user acceptance description of the form and content of the SFBC counseling guide for teachers BK SMPN 1 Kota Kediri. Some aspects that showed the acceptability of Solution Focused Brief Counseling guide of BK matter experts, media experts, and prospective users of the product include aspects of accuracy, relevance, clarity, and attractiveness. Each of these aspects is assessed by experts and potential users of the product as a whole showing the category very well.

Keywords: solution focused brief counseling, BK teacher, counseling service 


\section{PENDAHULUAN}

Bimbingan dan Konseling merupakan bagian dalam sistem sekolah yang memilkiki peran cukup besar dalam membantu perkembangan peserta didik. Guru BK sebagai pelaksana dalam praktik bimbingan dan konseling dituntut untuk selalu berkembang, memperbarui pengetahuan yang didapat, dan terbuka dalam menerima perkembangan ilmu pengetahuan yang ada. Neukrug (2007: 24) mengungkapkan bahwa guru BK yang efektif memiliki karakteristik, salah satunya yaitu Cognitve complexity. Guru BK mampu memandang dunia konseli dengan berbagai perspektif, sehingga mereka akan lebih empati, berpikir terbuka, dan memiliki kesadaran diri untuk selalu memberikan perubahan yang berarti demi meningkatkan profesionalismenya.

Salah satu bentuk profesionalisme guru BK dalam praktik konseling yaitu melakukan konseling dengan tahapan yang sesuai dengan pendekatan yang dilakukan. Berbagai pendekatan dalam konseling cukup beragam, dan salah satunya adalah SFBC (Solution Focused Brief Counseling) atau sering dikenal dengan konseling ringkas berfokus solusi. Konseling ini memfokuskan pada solusi yang dibangun oleh konseli, bukan pada masalahnya. Konseli diajak untuk membangun solusinya sendiri dengan berpegang pada kemampuan yang dimiliki konseli. SFBC merupakan pendekatan yang tergolong baru, sehingga banyak guru BK di sekolah yang belum terlalu paham dengan pendekatan ini. Pendekatan ini pertama kali diperkenalkan oleh Insoo Kim Berg pada tahun 1980-an, dan dapat digunakan untuk membantu mengatasi masalah siswa di sekolah.

Masalah yang dialami siswa di sekolah tentunya beragam dan memerlukan bantuan dari guru BK. Berbagai masalah yang dapat diatasi menggunakan pendekatan SFBC diantaranya, disiplin diri, kecemasan, efikasi diri, perilaku agresif, dan masalah-masalah dalam setting sekolah yang lain. Mengingat cukup kompleksnya masalah siswa, maka guru BK membutuhkan pendekatan yang efektif dan efisien. Oleh karena itu, pendekatan SFBC dipandang dapat membantu guru BK dalam mengatasi masalah-masalah di sekolah.

Kenyataan yang terjadi dilapangan menunjukkan bahwa para guru BK di sekolah belum mengenal pendekatan SFBC ini. Berdasarkan hasil observasi yang dilakukan peneliti di MGBK Kota Kediri terlihat banyak guru BK di sekolah yang belum tahu dengan pendekatan SFBC ini. Bagi mereka pendekatan ini merupakan sesuatu yang baru dan perlu diperkenalkan lebih jauh dalam praktik di lapangan. Mengingat pendekatan ini masih tergolong baru, para guru BK belum memahami tahapan jelas dalam proses konseling SFBC, sehingga mereka mengatakan perlu disosialisasikan lebih jauh terkait pelaksanaan pendekatan SFBC ini. Berdasarkan latar belakang tersebut, peneliti merasa bahwa perlu adanya panduan yang jelas dalam melaksanakan Solution Focused Brief Counseling (SFBC) agar guru BK di sekolah dapat mengaplikasikannya secara mudah. Oleh sebab itu, peneliti mengambil judul penelitian Pengembangan Panduan Solution Focused Brief Counseling untuk guru BK SMPN 1 Kota Kediri.

\section{KAJIAN PUSTAKA}

Solution Focused Brief Counseling (SFBC) pertama kali dipelopori oleh Insoo Kim Berg dan Steve de Shazer (Corey, 2012). Keduanya adalah direktur eksekutif dan peneliti senior di lembaga nirlaba yang disebut Brief Family Therapy Center (BFTC) Amerika Serikat tahun 1982. Insoo Kim Berg adalah juru bicara Konseling berorientasi solusi yang sangat berpengaruh.

Weishaar (dalam Corey, 2009: 375) menjelaskan bahwa secara filosofis, SFBC didasari oleh suatu pandangan bahwa sejatinya kebenaran dan Realitas bukanlah suatu yang bersifat mutlak namun Realitas dan kebenaran dapat dikonstruksikan. Pada dasarnya semua pengetahuan bersifat relatif karena selalu ditentukan oleh konstruk, budaya, bahasa atau teori yang kita terapkan pada suatu fenomena tertentu. Menurut konstruksionis sosial, Realitas didasarkan pada penggunaan bahasa dan umumnya merupakan fungsi situasi dimana seseorang berada.

Menurut O'Connell (2004: 1) Konseling Berfokus Solusi merupakan bentuk Konseling ringkas yang dibangun berdasarkan kemampuan yang dimiliki konseli. Konseling ini bertujuan untuk membantu konseli mencapai hasil yang diinginkan dengan membangkitkan dan membangun solusi dari masalahnya. Sedangkan menurut Jackson \& McKergow (2002: 1) Konseling Berfokus Solusi merupakan pendekatan yang sangat kuat, praktis, dan terbukti dapat mengubah positif individu, kelompok, dan organisasi. Konseling ini berfokus pada solusi, menolak pendekatan-pendekatan konvensional yang memberikan asumsi secara luas bahwa cara terbaik dalam menyelesaikan masalah adalah fokus terhadap masalahnya.

Charlesworth and Jackson (dalam Corey, 2012: 438) menjelaskan bahwa SFBC cocok untuk diterapkan dalam lingkungan sekolah. Adapun alasan-alasan yang melatarbelakanginya antara lain:

a. Guru BK dapat melakukan Konseling secara efektif kepada siswa dengan waktu yang singkat.

b. Pendekatan SFBC mengutamakan pentingnya perubahan kecil dan membangun tujuan bersamasama.

c. Pendekatan SFBC membantu siswa mengembangkan tujuan positif daripada fokus dalam mendorong siswa berhenti melakukan hal yang negatif.

d. Pendekatan SFBC merupakan pendekatan yang efektif dan praktis karena lebih menekankan sesuatu hal yang harus dikerjakan daripada menghentikan permasalahan. 
e. Pendekatan SFBC bisa menerima dan manjadi penghubung atas perbedaan pendapat dan keyakinan dimana kondisi ini banyak ditemui di lingkungan sekolah karena memiliki siswa yang beragam.

f. Pendekatan SFBC memiliki konsep yang jelas dan relatif mudah untuk dipelajari.

g. Pendekatan SFBC lebih kuat dalam menyelesaikan masalah daripada pendekatan yang langsung didasarkan pada gangguan psikologis dan perilaku disfungsional.

Walter \& Peller (dalam Corey, 2012: 430) menjelaskan ada empat tahapan SFBC sebagai berikut:

a. Mencari tahu apa yang anggota kelompok inginkan daripada mencari apa yang tidak diinginkan.

b. Tidak mencari patologi dan tidak mencoba untuk mengurangi kemampuan anggota dengan memberi label diagnostik. Sebaliknya, mencari apa yang anggota lakukan yang sudah bekerja dan mendorong anggota untuk terus ke arah itu.

c. Jika apa yang anggota lakukan tidak bekerja, mendorong anggota untuk bereksperimen dengan melakukan sesuatu yang berbeda.

d. Menjaga Konseling berlangsung ringkas dengan mendekati setiap sesi seolah-olah itu adalah sesi terakhir.

Beberapa teknik yang digunakan dalam SFBC antara lain (Corey, 2012: 433):

a. Perubahan pra-sesi (Presession Change)

Salah satu ciri khas pendekatan SFBC adalah perhatian yang berfokus pada solusi untuk perubahan yang sudah muncul sebelum sesi pertama. Solusi berfokus pada perubahan alami dan terjadinya konstan yang menjadi harapan konseli karena mereka berjuang untuk mengubah apa yang awalnya tampak sebagai masalah besar yang mereka takuti. Guru BK mengajukan pertanyaan "sejak Anda dipanggil, sampai kita bertemu pada pertemuan pertama ini, ada perubahan apa yang Anda dapatkan?'

b. Pertanyaan

Pertanyaan menjadi alat komunikasi dan intervensi utama. Pemimpin kelompok menggunakan pertanyaan sebagai cara untuk lebih memahami pengalaman anggota kelompok bukan hanya untuk mengumpulkan informasi. Pertanyaan diminta dari posisi hormat, keingintahuan yang tulus, minat yang tulus, dan keterbukaan. Jawaban anggota kelompok memberikan informasi yang merangsang kepentingan pemimpin, dan pertanyaan lain berlangsung dari setiap jawaban yang diberikan. Anggota kelompok lainnya didorong untuk merespon bersama dengan pemimpin kelompok untuk mempromosikan kolaborasi kelompok. Menciptakan proses kelompok kolaboratif sangat penting untuk keberhasilan kelompok.

c. Pertanyaan pengecualian (Exception Question)

Pertanyaan pengecualian digunakan untuk mengarahkan konseli ketika masalah yang dialaminya tersebut tidak ada. Pengecualian merupakan pengalaman masa lalu dalam kehidupan konseli ketika dia mempunyai beberapa harapan masalah tersebut terjadi, masalah tersebut tidak semuanya kuat dan tidak selamanya ada.

d. Pertanyaan keajaiban (Miracle Question)

Guru BK meminta konseli untuk berimajinasi bahwa suatu keajaiban akan terjadi di masa depan. Konseli didorong untuk membiarkan dirinya bermimpi tentang suatu cara untuk mengidentifikasi perubahan yang mereka inginkan. Pertanyaan keajaiban mempunyai fokus pada masa depan dimana konseli menginginkan kehidupan yang berbeda yang tidak berkutat pada masa lalu dan sekarang tetapi pemuasan hidup di masa mendatang.

e. Pertanyaan berskala (Scaling Question)

Pertanyaan skala memberikan kemungkinan pada konseli untuk lebih memperhatikan apa yang telah mereka lakukan, dan bagaimana mereka mengambil langkah yang akan mengarahkan pada perubahan yang mereka harapkan.

f. Rumusan tugas sesi pertama (Formula First Session Task)

Formula First Session Taskadalah suatu format tugas yang diberikan guru BK kepada konseli untuk diselesaikan antara sesi pertama dan sesi kedua. Guru BK berkata, "diantara hari ini dan pertemuan kita selanjutnya saya berharap Anda dapat mengamati, sehingga Anda dapat menjelaskan kepada saya pada pertemuan mendatang tentang apa yang terjadi dalam kegiatan belajar atau prestasi akademik Anda". Pada sesi kedua, konseli dapat ditanya tentang apa yang telah mereka amati dan apa yang mereka inginkan dapat terjadi di masa yang akan datang.

g. Umpan balik (Feedback)

Guru BK pada umumnya mengambil waktu 510 menit pada akhir setiap sesi untuk menyusun ringkasan atau kesimpulan Konseling. Guru BK memformulasikan umpan balik yang akan diberikan pada konseli. Pemberian umpan balik memiliki tiga hal yaitu sebagai pujian, jembatan penghubung, dan pemberian tugas.

\section{METODE}

Model pengembangan panduan Solution Focused Brief Counseling (SFBC) menggunakan adaptasi model pengembangan yang dikemukakan oleh Borg and Gall (1983). Pada dasarnya model pengembangan ini memiliki dua tujuan utama, yaitu mengembangkan produk dan menguji keefektifan produk. Dalam penelitian ini, peneliti tidak menggunakan tahap-tahap di atas secara keseluruhan. Penelitian dan pengembangan ini menggunakan tujuh tahap yaitu 1) tahap pengumpulan data; 2) tahap perencanaan; 3) mengembangkan produk awal; 4) uji coba terhadap ahli materi BK dan media; 5) revisi media; 6) uji calon pengguna produk, dan 7) revisi tahap akhir.

Prosedur pengembangan panduan Solution Focused Brief Counseling (SFBC) ini diadaptasi dari prosedur penelitian Borg and Gall (1983). Peneliti tidak 
sepenuhnya menggunakan model pengembangan Borg and Gall. Pengembangan SFBC dilakukan sampai pada tahap uji calon pengguna produk. Adapun langkahlangkah prosedur penelitian tersebut adalah sebagai berikut:

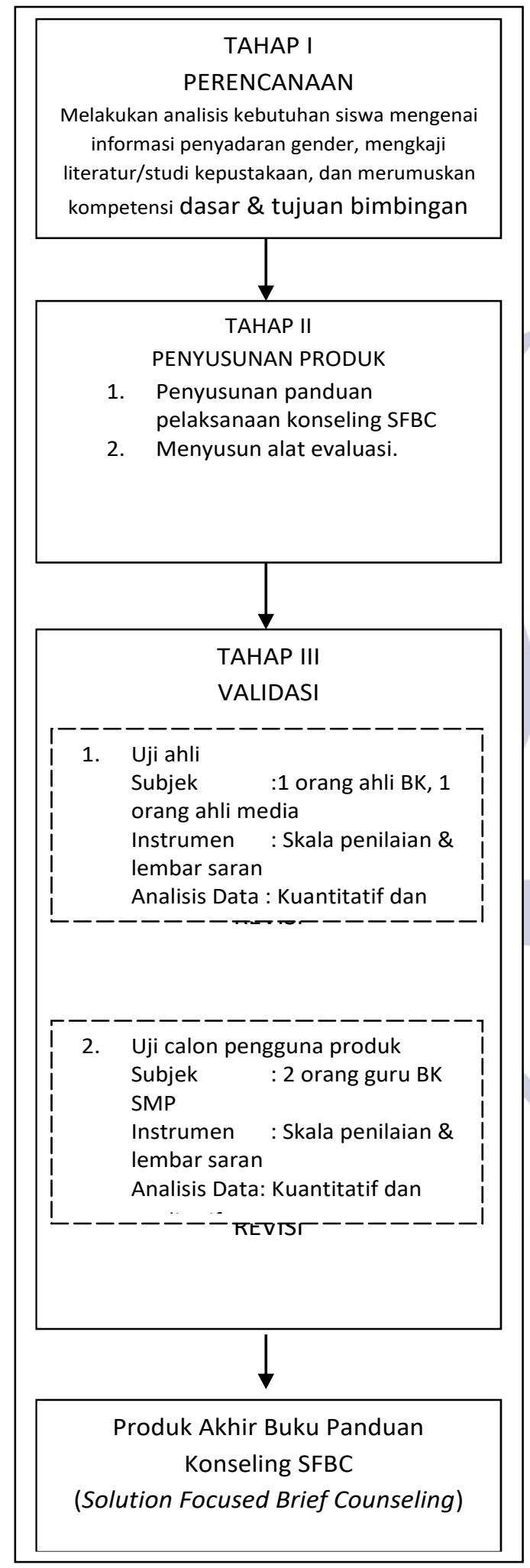

Gambar. Prosedur Penelitian Model Borg and Gall

\section{HASIL DAN PEMBAHASAN}

Berdasarkan penilaian uji ahli dan calon pengguna produk, didapati bahwa panduan Solution Focused Brief Counseling dapat diterima dari segi bentuk dan isi. Hal tersebut dilihat dari penilaian uji ahli yang menunjukkan kategori sangat baik, dan uji calon pengguna produk menunjukkan kategori baik. Meskipun panduan tersebut sudah layak untuk dijadikan sebagai media dalam proses pemberian konseling kepada siswa, peneliti tetap memperbaiki isi dan bentuk media sesuai saran/ masukan dari para ahli.

Panduan Solution Focused Brief Counseling terdiri dari pendahuluan, patunjuk umum, dan petunjuk khusus. Di dalam pendahuluan terdiri dari pengantar untuk guru BK, dan prosedur umum konseling SFBC. Sedangkan pada petunjuk umum terdiri tujuan, sasaran pengguna, dan pelaksanaan intervensi konseling SFBC. Pada petunjuk khusus terdiri dari pra konseling, sesi pertama, sesi kedua, sesi ketiga, dan sesi keempat. Peneliti di dalam panduannya juga memasukkan contoh dialog yang dapat digunakan oleh guru BK dalam praktik konseling SFBC tersebut. Berdasarkan masukan dari uji ahli secara keseluruhan sudah baik meskipun ada hal-hal yang harus direvisi. Guru BK sebagai calon pengguna produk mengungkapkan bahwa adanya panduan Solution Focused Brief Counseling sangat membantu dalam proses pengenalan pendekatan tersebut, mengingat pendekatan ini tergolong baru.

Solution Focused Brief Counseling merupakan pendekatan yang ringkas dalam artian lebih menonjolkan solusi yang dibangun oleh konseli sendiri. Konseli dianggap sebagai pribadi yang berkompeten, yang mampu mencari solusinya sendiri tanpa tergantung dengan guru BK. Hal tersebut seperti yang diungkapkan oleh Corey (2012: 425) bahwa Solution Focused Brief Counseling merupakan pendekatan yang berfokus pada masa depan, berorientasi tujuan. Meskipun pendekatan ini tergolong baru, guru BK harus terus mengupdate pengetahuannya tentang konseling yang menjadikannya sebagai pribadi yang open minded.

\section{SIMPULAN}

Berdasarkan hasil penilaian uji ahli materi BK, ahli media, dan calon pengguna produk, maka diperoleh deskripsi penerimaan pemakai atas bentuk dan isi dari panduan konseling SFBC untuk guru BK SMPN 1 Kota Kediri. Beberapa aspek yang menujukkan keberterimaan panduan Solution Focused Brief Counseling dari ahli materi BK, ahli media, dan calon pengguna produk meliputi aspek ketepatan, kesesuaian, kejelasan, dan kemenarikan. Tiap aspek tersebut dinilai oleh para ahli dan calon pengguna produk yang secara keseluruhan menunjukkan kategori sangat baik.

\section{SARAN}

Diharapkan Solution Focused Brief Counseling dapat digunakan secara luas tidak hanya untuk Guru BK di SMPN 1 Kota Kediri tetapi juga guru BK di SMPN lain di Kota Kediri. Melalui panduan ini juga diharapkan guru BK lebih mudah dalam mengaplikasikan Solution 
104 | Pengembangan Panduan Solution Focused Brief Counseling Untuk Guru Bk Sekolah Menengah

Pertama Negeri (Smpn) 1 Kota Kediri

Focused Brief Counseling sebagai salah satu alternatif dalam pemecahan masalah.

\section{DAFTAR RUJUKAN}

Borg, W.R. \& Gall, M.D. 1983. Educational Research: An Introduction. London: Longman, Inc. Cohen, Bruce.

Corey, G. 2009. Theory and Practice of Counseling and Psychotherapy. ( $8^{\text {th }}$ edition). Belmont, CA:

Brooks/Cole.

Corey, G. 2012. Theory and Practice of Group Counseling $\left(8^{\text {th }} \quad\right.$ Ed $) . \quad$ Belmont, CA: Brooks/Cole.

Jackson, P.Z. \& McKergow, M. 2002. The Solutions Focus The Simple Way to Positive Change. London: WS Bookwell.

O' Connell, B. 2004. Solution Focused Stress Counselling. London: Sage Publication.

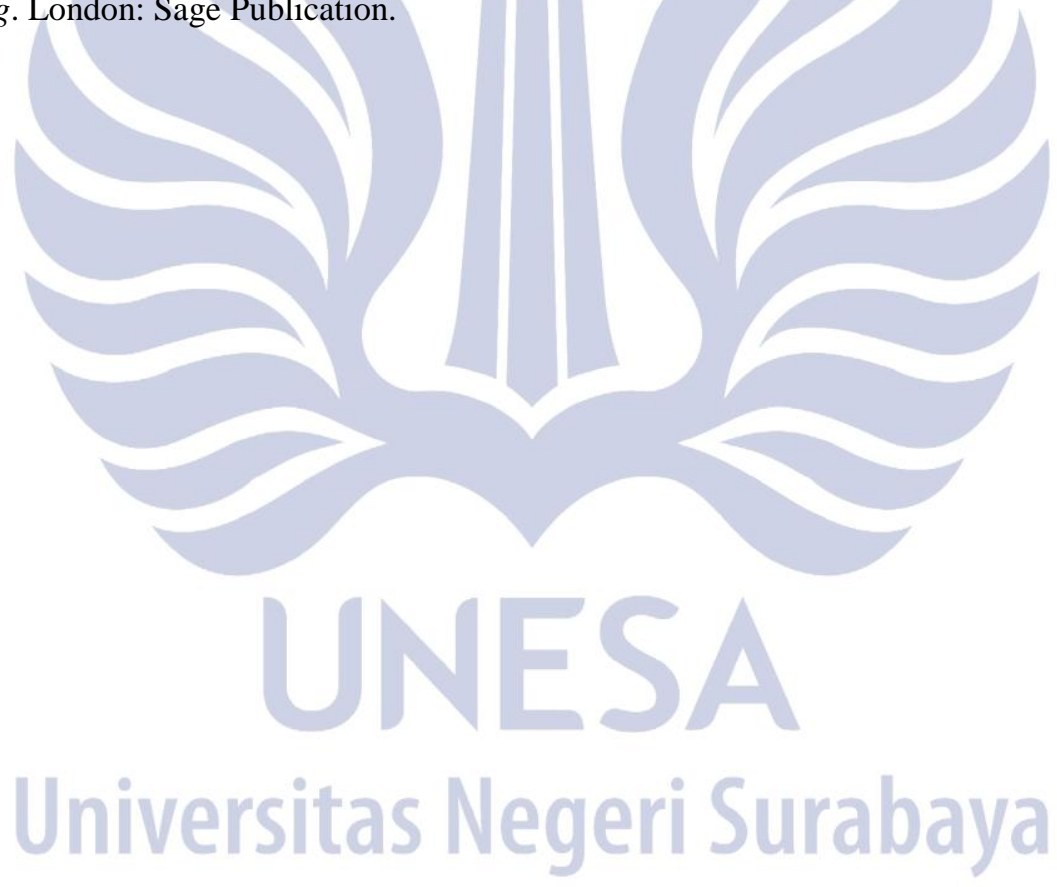

